\title{
Teacher and student perspectives on one-to-one pedagogy: practices and possibilities
}

\author{
Gemma Carey and Catherine Grant
}

Queensland Conservatorium, Griffith University, P0 Box 3428 South Bank, Q 4101 Australia

g.carey@griffith.edu.au; catherine.grant@griffith.edu.au

This paper explores teachers' and students' perceptions of one-to-one pedagogy, in the context of tertiary vocal and instrumental tuition. Teachers and students at one Australian conservatoire participated in interviews and focus groups that explored their experiences and perceptions on the nature, value, effectiveness and challenges of one-to-one learning and teaching. Four key themes emerged: customising teaching to the learner, the teacherstudent relationship, negotiating issues of student dependency versus self-sufficiency, and situating one-to-one in a broader institutional context. Aside from an undisputed view that one-to-one is essential to students' learning and development, findings indicate diverse perceptions, including discrepancies between intentions of teachers and their pedagogical practice, and between teacher practice and student expectations. By drawing on voices 'from the inside' to characterise one-to-one practice, the study contributes to evidencebased research about learning and teaching in the conservatoire environment.

\section{Introduction}

Research into higher music education conveys an overwhelming sense that the one-toone model of instrumental and vocal tuition plays a valuable, even irreplaceable, role in the training of professional musicians (Kennell, 2002; Purser, 2005; Burt \& Mills, 2006; Gaunt, 2008, 2010). Individual lessons are widely viewed as an 'indispensable, intense and intricate' part of instrumental and vocal learning (Gaunt, 2008, p. 230), and remain the clear pedagogical model of preference for delivering a 'serious' vocal and instrumental music education (Harrison, 2004, p. 4). Conservatoires continue to display considerable respect for the one-to-one model, promoting its existence as an 'internationally recognised' standard of teaching, one that needs to be 'safeguarded' for a country to remain musically competitive on the international scale (Harrison, 1997; MCA, 2011). One-to-one instruction therefore still serves as the primary method by which tertiary music students receive their practical skills and performance-based training (Association of European Conservatoires (AEC), 2010).

Criticism of one-to-one conservatoire tuition is, however, not unusual (e.g. Schmidt, 1989; Persson, 1996; Kennell, 1997; Froehlich, 2002; Presland, 2005; Burwell, 2006; Carey, 2008). Some studies suggest that this model can have a negative effect on students (Persson, 1994; Burwell, 2006) particularly in relation to its perceived teacher-centredness (Polifonia, 2010). Others claim that in one-to-one teaching, 'musical skill development can be erratic', and students often lack the ability to adapt their learning to diverse musical 
contexts beyond the teaching studio (Mills, 2002). Carey (2010) proposes that one-toone can have long-term adverse effects on the student as learner, leading to dependency, limited employment opportunities and disillusionment. Moreover, despite the growing scholarly literature on one-to-one and the continued prominence of this model in music training, little empirical evidence of its unique benefits or effectiveness exists; its success is still largely measured in terms of students' ability to succeed in performative events such as competitions and recitals. Compounding the problem is the fact that most one-toone teaching and learning happens behind closed doors, making research access difficult (Gaunt, 2008, 2010). By advancing evidence on one-to-one, an aim of this research is to further break down the 'secretive nature' of this pedagogical model (AEC, 2010) and the culture of concealment that has characterised it in the past (Carey, 2008).

Research that aims to better understand and improve one-to-one pedagogy is also timely in the present milieu: many institutions are being called to justify the educational value of this costly model in the face of funding cuts, institutional amalgamations, internal restructures and a fast-changing cultural environment (Lockett, 2007; Carey, 2008; Maze, 2012). Since improving instrumental and vocal teaching will - arguably by definition improve learning outcomes (Burwell, 2005; Gaunt, 2011), continual development and improvement of exemplary practice models is essential. Research that gives voice to teachers and students (e.g. Mills, 2002; Mills \& Smith, 2003; Presland, 2005; Gaunt, 2008, 2010, 2011), the two groups of people best able to provide 'insider' insight on current practices and future possibilities for one-to-one, will likely play an important role in this process of improving teaching and learning practice. Founded on this premise, this study juxtaposes and analyses teacher and student perspectives on the nature, value, effectiveness and challenges of one-to-one teaching and learning.

\section{Context and method}

This study forms part of a larger research project being conducted within one Australian conservatoire, an institution with an enrolment of over 600 undergraduate and postgraduate students majoring in performance, composition and pedagogy. Through interviews, focus groups and videoed lesson observations, the project seeks to generate empirical evidence about one-to-one learning transactions in the conservatoire context; to explore and document the processes of one-to-one teaching and learning; and to systematically reflect on how those processes might be made more effective. This paper reports on the outcomes of the teacher interviews and the student focus groups only.

A core philosophical underpinning of the wider project is its emphasis on collaborative enquiry involving teachers and students as well as researchers, in the belief that improving pedagogical practice requires a commitment to reflective discussion with those involved. For this reason, throughout the larger research project of which this study is a part, the research team was eager to foster a sense of partnership, encouraging teachers in particular to adopt a degree of ownership and control of the research direction. The researchers have prioritised open communication, trust-building and identification of clear roles and responsibilities - all hallmarks of beneficial partnerships in music education itself (Hallam, 2011). By working with and for, rather than simply on or about, teacher-participants in this way (Carey et al., 2012), it was also hoped the research design would limit teacher 
scepticism and reluctance to participate in research on one-to-one that has been observed in the context of other research projects (Gaunt, 2008, 2011).

Two methods of data collection were used in this study. For teacher-participants, the format of semi-structured interviews was chosen for its capacity to serve as a platform for indepth storytelling and reflection, including complex (and sometimes political) institutional issues. In an effort to maximise openness on the part of the teachers, interviews were conducted by two external researchers, and lasted approximately one hour. Of the 12 teachers who volunteered to participate, eight were selected according to the criterion of achieving a representative sample of performance specialisms, full-time and part-time teachers and gender balance. Selected participants comprised five full-time and three parttime teachers in the areas of Keyboard, Strings, Voice, Woodwind, Brass and Percussion (see Appendix, Table 1). The researchers gave teacher-participants a written summary of the project rationale and methodology, and met with them as a group to discuss the project two weeks prior to the interviews. Risks and benefits of being involved in the research were discussed at this meeting; university ethical clearance had already been granted for all phases of the project. In the interviews, teachers were invited to respond at length to a single open-ended question: 'What makes one-to-one tuition effective?'

Students from all performance areas were invited to take part in the study. Eighteen students volunteered (15 undergraduate, 3 postgraduate; 12 female, 6 male), with each performance area at the institution sufficiently represented (see Appendix, Table 2). Four semi-structured focus groups of an hour's duration were conducted, each comprising four or five students. Students were invited to reflect on their perspectives and experiences of one-to-one tuition, and on what makes it effective. Stimulus topics included: What do you find helpful or valuable about the one-to-one model? What challenges arise? How would you describe the nature of the teacher-student relationship? What is the role of the teacher? If you were to describe the experience of one-to-one learning, what words would you use? In accordance with university ethics protocols, student-participants were provided with an information sheet and a consent form about their involvement, and were assured confidentiality and anonymity in all outcomes of the research.

All focus groups and interviews were audio-recorded, transcribed and analysed. The researchers undertook thematic analysis independently and then jointly. Four broad themes emerged: customising teaching to the individual; the student-teacher relationship, student dependency versus self-sufficiency; and situating one-to-one teaching in a wider context.

\section{Findings}

In this section, $M / F$ refers to the gender of the participant. ' $T$ ' indicates teacher; ' $F G^{\prime}$ followed by a numeral indicates the number of the focus group from which student quotes are taken (see Appendix 1).

\section{Customising teaching to the individual}

For both student and teacher participants in the study, the potential to tailor teaching to the needs and goals of the individual student was a vital part of what makes one-to-one valuable 
and effective. For teachers, priorities included treating each student as an individual, reacting to students' changing needs and providing the right learning environment:

T2 (M): The most important aspect of the one-to-one teaching is the development of techniques specific to the individual, because each player comes with a different set of challenges ... So that, to me, is the most important aspect: just you and I sitting in a room nutting out what it is that's specific to your needs.

T7 (F): [The one-to-one situation] gives you the ability to customise your teaching approach to the learner, and to ... bring all your pedagogical tools to bear on facilitating learning for that individual student. So [it gives you] the ability to tailor everything to their needs, their particular style of learning, what sort of learner they are and their range of needs - where they're at physically, musically.

T4 (F): If I was to bring it back to one foundational thing, it's that I deal with each student as an individual.

For students also, the primary value of the one-to-one model resided largely in its ability to cater for their individual needs. Some students, for example, referred to this at the micro-level, focusing on issues relating to technique:

FG1 (F): You'll go into the [teaching] room and you'll find something you're struggling with technically, and [the teacher] would go to his little cupboard and he pulls out an exercise, or a study that he knows specifically targets that thing, and give it to you. It's like almost going to the doctor and being like, 'This is my problem', and he prescribes the medicine.

FG3 (M): With the one-to-one tuition, your teacher just looks at what you're doing wrong and says, that's wrong. Here's how to do it right. ... You look at that and go, oh okay, my hand needs to go like that instead. So you just do it.

Others referred to the tailored nature of one-to-one in broader terms:

FG1 (F): With one-to-one lessons, the teacher and the student together can cater for you and spend time finding a programme or a plan that will suit that person, will suit me, looking at my weak points, things that I can improve on. And I think that really helps to have just that individual attention and focus.

FG4 (F): I really like that you're actually able to guide the learning in a way that actually suits you.

FG3 (M): When you teach [one-to-one], you're teaching ... what that person needs to know at this particular point in their stage of development.

One student drew on an analogy to describe the value of tailoring one-to-one teaching in terms of artistic outcomes: 
FG3 (M): When you see chairs at Aldi or at Ikea, all of that stuff, then you go to a woodworker who's gone and turned the legs for his wardrobe, there's just no comparing, because one is a manufactured piece ... [a] mass-produced thing, and the other is a completely personal piece of art. Right here at the Conservatorium, we're creating art.

Not all students were confident that the curriculum created for them by their teacher was adapted to their individual needs:

FG1 (F): Sometimes there's times when I feel [one-to-one] is ... maybe not structured to me ... because I see everyone else seems to be doing the same repertoire. Particularly with choosing your repertoire, I think that should be really based around your interests and things you enjoy doing, because you've got to try and enjoy what you're playing.

In fact, some students spoke of the necessity to customise their learning to the teacher, rather than vice versa.

FG1 (F): I thought my teacher would ... change their teaching style for me, and that didn't happen, and at first I was quite frustrated with that. ... But I think over time I've just adapted to my teacher's style of teaching.

One student asserted that adapting to the teacher's style in this way was a necessary part of one-to-one learning:

FG2 (M): I think it's necessary [for the student to adapt to the teacher]. Certainly I've had to do that, because every teacher that I've learnt from has had a different teaching style to some extent, so I've had to adapt to that different style, and also had to adapt my playing technique, because each teacher has had different views on how technique should be developed.

\section{The student-teacher relationship}

While teacher and student participants generally considered customising one-to-one important, views of both groups varied considerably regarding the optimal nature of their relationship. One teacher suggested that teachers fulfil a mentorship role for students, including guiding them in matters beyond the musical:

T5 (F): The one-to-one apprenticeship system provides the student with a mentor who develops solutions for all the problems they might encounter. ... It is the uniqueness of each individual that the teacher is trying to foster and support.

Students also referred to teachers as role models or mentors. Some spoke of this primarily in musical and professional terms.

FG2 (F): It's inspiring to be around someone like that, to hear someone play like that, and to hear someone play something you are playing ... It's nice to be able to idolise 
someone - not in a weird way or anything, just like, I can say, 'Oh wow, that's really what I want to be able to do'.

Others also commented on the way teachers acted as role models in areas beyond the musical.

FG1 (M): I always like to think of [one-to-one] as a journey, that they share your journey with you. How deep! That's in all facets of your life, mostly musical of course because that's why we're here. Then also I think we're growing up as well, because you come in out of high school - you're still very immature. So I do think that they have a bit of a role in shaping you as an adult citizen. Yeah, I really like the idea of having the teacher as the friend and the role model.

FG2 (M): I think it helps if your teacher is able to inspire you, and not only with their playing, but also with their attitude to music making and to students, and even with their work ethic. I'm really inspired by one of my current teachers. He's 70 years old and still teaching, and still really passionate about music, and that really inspires me, because I'd like to be passionate about music like that when I reach that age.

FG2 (F): My old [former] teacher who I still see for lessons, I would say that he's a role model ... Whenever I start feeling too worried about where my life is going, I just think, you know, this is exactly what he did and I look at his life and I'd be happy with that life in 10 years' time. So I feel maybe I don't need to worry so much.

Likewise, for teachers, the teacher-student relationship also extended beyond artistic or technical matters. One teacher valued the 'customisable' nature of one-to-one for its ability to prepare each student for a successful career, for example by developing in students a range of generic skills essential for the music profession.

T5 (F): One-to-one is indispensable for serious career preparation at the professional level, where the student needs time away from the herd in order to develop an original and personal approach at their musical instrument. ... [One-to-one is important for] tailoring for their possible future path, because by no means does one size fit all. I mean, there's a lot of [possible] career outcomes in this place.

In addition to students perceiving their teacher as mentor, many also spoke strongly of the importance of having a close friendship with their teachers.

FG3 (M): I think of him [my teacher] as more of a friend. ... There's so many extra things that you can ask them to do, because they're not just some random person who you see once a week. I'll text him all the time - hey, what do you think about this? Can we do this? What should I wear to this audition? All these personal things.

FG1 (F): I think most students want to talk to [their teachers]. They go into the lessons and the person is a teacher but they're also a role model and also sometimes your friend ... So I think that's really nice. 
FG2 (M): The relationship is important personally for me. Every single one of my [oneto-one] teachers I'm still friends with. My current teacher now, I definitely know that I can discuss anything with them whatsoever, and feel confident in their confidentiality as well. It could be anything that you could speak to them about. That interpersonal relationship is important, I think anyway.

One student described a close relationship with his teacher, in which 'If there's a problem she'll talk to you about it':

FG1 (M): Every problem, mental, life, emotional, social. Some people would think that's a little bit too intrusive, but it depends on the person, and I quite like [it].

Another student commented that a friendship with a teacher improved his ability to learn. When asked what optimises learning in a one-to-one environment, this student replied:

FG3 (M): That the relationship between you is good enough that you can communicate on a level as friends, as well as teacher-student, because I think that allows for quicker learning.

Two students, though, expressed regret at their teacher's lack of interest in them as people:

FG2 (F): I reckon the best teachers are the ones who you think actually care how you go. I don't really feel like my teacher here really has any interest in how I fare outside of my study right here, whereas my other teachers [do].

FG2 (M): I know for example my piano teacher here isn't really interested in me, or doesn't seem to be interested in me beyond my actual playing. It's almost as if I'm just two hands walking into a room, into her teaching room, once a week for an hour and a half that then walk out again at the end of that hour and a half.

Another described how she approached overcoming this problem:

FG1 (F): [Recently] I spoke to my teacher about goals, just not pure musical goals but my academic goals and what I want to do after uni, and just basically opened up and said, 'This is me' so they don't just see me in a lesson once a week and ... associate me with some pieces .... It's like no, actually do you know what academic subjects I'm taking? Do you realise that I'm not just interested in the practical side of music? I'm interested in research and the academic side of things. I think ever since then things have turned around.

While some students inferred that the teacher-student relationship should ideally resemble (or in fact be) a friendship, others expressed a view that 'getting too close' may jeopardise teacher authority and student respect, and preferred to keep a professional distance in the relationship.

FG2 (F): I'd call it amicable, but I don't tend to take him any problems. ... I would just say it's fairly - maybe professional is a good word for it. We focus on the music. 
FG1 (M): [My one-to-one teacher is] definitely my guide and I respect them, but they're not my friend. It's not a personal thing. It's almost for me [like being] business partners in a way. I don't want to come in and high-five my teacher.

One student even argued that a friendship with a teacher may negatively impact learning:

FG4 (F): I think ... you have to have that little bit of respect and even be a little bit ... afraid of disappointing them so that next week you come back and you do better, because if you're 'besties' you can be texting them, 'No, I didn't practice this week' whereas every lesson I come back and I'm like, 'I have to do better.'

Similarly, some teachers maintained that keeping 'a certain personal distance' was indeed in the student's best interests:

T5 (F): I don't become personally involved. My hellos are in fact ... probably disgraceful. ... I just try to make it, 'Hi, how did C major go this week?' - bang. ... The teacher may become too invasive and controlling in the student's private life. ... A certain personal distance is advisable.

Another adopted a more authoritarian approach:

T1 (M): I don't think I'm tough enough on a lot of [my students]. I've toughened up considerably ... I realised that there were a couple of students that had just basically gotten away with far more than they should have, and I had let them get away with it. So yeah, I've toughened up a bit on just basically following the protocols ... this is the deadline, this is when it has to be done, this is what has to be done, and there's no flexibility. I think once the students realise that then everyone has a much better experience ... They've got to perform these chores ... you've got to learn your scales, you've got to learn your repertoire ... you have to be on time.

\section{Student dependency versus self-sufficiency}

In addition to differing views on the optimal nature of the teacher-student relationship, participants spoke of further challenges in relation to student- versus teacher-led learning. Discussions with teachers about pedagogical approach prompted varied responses in terms of encouraging student self-sufficiency in the course of one-to-one teaching.

All teacher-participants expressed an intention to foster student independence.

T3 (F): I don't want to churn out replicas of myself - far from it. I'd rather [students] retain their own voice, which I think you can still do with more verbal guidance [than modelling] ... I think the big thing is [students] ... coming out of school and then going into university ... They're used to being a lot more looked after. ... But when they get to the Con I always try and promote musical independence.

One teacher gave an example of how the intent to create student self-sufficiency manifests in her teaching approach: 
T4 (F): My main goal is to make [students] self-sufficient, by giving them these physical tools, things that they can control ... when I talk to them in terms of what the muscles are doing, or this is how you arrange your body ... then that belongs to them. It doesn't belong to me anymore. They've taken ownership of it.

Many students agreed that they, not their teacher, should take responsibility and ownership for their learning:

FG4 (F): I know some [students] don't really direct, maybe don't use the opportunity to direct their lessons the way they want. Then they're the ones who complain about their results. If they're not getting the results they want from the lessons it's generally because they're not taking the opportunity to just guide it in the direction of what they actually want to learn.

FG1 (M): It's a two-way street, not a one-way street.

FG4 (F): A teacher can only do so much in a one-to-one situation. They can only give you so much direction before you have to take it on yourself.

However, one student regretted not being given the opportunity to take responsibility for his learning:

FG2 (M): I subscribe almost completely to ... his methods. I do exactly what he wants and that's the way that I get the most out of the lessons from him, because if I come to him and I say, 'No, actually I think it should be like this', he'll just tell me to get stuffed.

Faced with a teacher who did not adapt to her learning needs and style as fully as she had expected, another student simply adapted to her teacher's style over time. This resulted in an ambiguous dependency relationship:

FG1 (F): I think over time I've just adapted to my teacher's style of teaching, and I think that's actually probably been pretty beneficial to me, because I guess if I just stayed in my own little way of having lessons and doing practice my way and just learning in the way I've always been taught, I probably wouldn't have [grown]. ... I'm quite happy to follow where my teacher is going now.

However, both teacher and student participants referred to the potential for some students to struggle in an environment where independence was encouraged. One student spoke of being 'thrown in the deep end' when she commenced one-to-one studies at the Conservatorium:

FG1 (F): I walked in and my teacher asked me what technique I wanted to do, studies I wanted to do, and I just felt in my first year: I need you to give me something that I can just grasp on to, for even just a semester, and then through one-to-one teaching we can work on that and then I'll form some ideas. So I just felt maybe like the one-to-one teaching was great, but I felt maybe I was thrown into the deep end. 
One teacher reflected on situations like these, and how he deals with them:

T2 (M): Young students ... who are extremely high achievers actually struggle with this [less prescriptive] environment. [With them] I'm much more prescriptive. [I] give them a daily practice plan and say, 'You stick to that. Don't go outside of those parameters.' Then they love it, because they're used to it. ... I do find that sometimes those academically high-achieving students sometimes struggle within a less prescriptive environment.

This teacher added:

T2 (M): [High-achieving students] want to be told, they want to be directed. ... That's not true of the industry, so it's about teaching them to learn how to learn.

This teacher's approach appears to contradict his philosophy that students need 'to learn how to learn'.

T2 (M): The first half of the lesson is mimicry, watching what I do, see[ing] if they can copy, and then we branch out into what they're good at, what they're not so good at, and what they're terrible at - without focusing too much on the terrible early on. That comes later. By the time they're a fourth-year, they know all the routines we do together. We might do five, ten minutes of what I call ... exercises, which gets them set up for the lesson. ... We do that together, because I think the mimicry is vitally important. ... So they know, they walk in, they sit down. We don't even talk. They know exactly what we're going to do before we even do it.

Additionally, this teaching method appears to conflict with the learning approach of some students, who clearly prefer independent thinking to the practice of mimicry.

FG4 (F): I don't really want to follow my teacher's idea because I don't really think that's particularly tasteful ... so that can be an issue at some points.

While some actively sought to ensure independence from the start of tertiary studies, a number proposed that students should begin their studies with close teacher guidance and be encouraged to become more and more independent as they progress through their degree.

T7 (F): My opinion is that early and beginning students ... are not able to work effectively independently. Therefore the idea of seeing your teacher one hour a week and having that whole seven days to go away and practise things incorrectly is really not very productive. I think in actual fact ... that we sort of do it round the wrong way. We have one lesson [a week] in year one ... and when we get to senior years we bulk up on the lesson contact time ... In actual fact it needs to go the other way, I think, [so that] you're ready to go into the next stage of your learning or enter professional life having achieved greater independence from your teacher rather than increased contact and dependence as you get more advanced. 
T2 (M): I think actually the longer lessons should be the first-years and the shorter lessons should be towards the fourth year. ... [It's] the younger ones that need more time ... With senior students ... we spend a lot of time just playing music and looking at repertoire and investigating things outside of required technique.

T3 (F): In first year I'Il be playing more, and then in second and third perhaps less and less ... By fourth year I would say probably the lessons are more free and not as structured as such, and way more student-directed than teacher-directed, for sure, because they've got a clearer idea of what their personal goals are.

Increasing levels of independence during a course of study was not a key theme raised by students.

\section{Situating one-to-one in a broader context}

Within the institution in which this research is situated, alternative (non-one-to-one) models of teaching and learning include group lessons, workshops and student-led sessions, as well as situations where students are taught individually by two or more teachers who take different roles in the teaching and learning process. Half of the teacher-participants in the study indicated strong support for working collaboratively with colleagues, to enhance and broaden both their own and their students' experiences of one-to-one.

T7 (F): I'm a teacher who is very committed to [an] inter-disciplinary approach to teaching and learning, so I frequently bring other ... professionals into my studio. What I feel is that not only brings greater expertise to the studio, which I benefit from as well as the student, but it's also mirroring professional life where you learn to take instruction from a variety of sources. It also allows the student to really understand that there is never any real one source of information [in] learning. ... While your teacher ... is probably one of the most important people in your life for those three or four years, that they're not the only person from whom you will be learning.

Another teacher instigated the adoption of a team teaching approach within her area, where students rotate between different teachers in their first two years of study, and choose a combination of teachers to work with in their third year. In her opinion, both teachers and students benefited from this practice of team-teaching:

T4 (F): I explain to the students when they first come here that they're going to get the strengths of all of those teachers ... I like being in a team. I like the collegiate [nature of it]. I think the student benefits from that.

One teacher commented on advantages of holding workshops in conjunction with one-toone lessons:

T8 (M): Then you'll get some feedback from the other instructors if they're taking a class, and also from your other colleagues. ... We encourage a nice collegial atmosphere of people encouraging each other and critiquing in a polite way. 
While teachers unanimously agreed on the need for all students to engage in an 'intense' amount of one-to-one tuition, five teachers spoke of the advantages of conducting one-toone lessons in combination with various other models or formats.

T2 (M): I train my students in particular in this whole element of teamwork and ensemble work and in small groups, and also playing for one another, learning to identify someone else's weakness in order to identify your own weaknesses and strengths. ... So every [week] I have the entire [area] together. We meet ... and do an hour together in a group ... then we'll debrief ... we sit and we chat as a group. I usually get my senior students to direct that because they've done it before. They look after the younger ones .... They do a lot of corridor-walking for practising and stuff, see how you're going.

T7 (F): I think what I have found is the most effective is to have that individual time, but then also incorporate the learning in a group setting [like workshop].

While acknowledging that 'it would be very good if we did have some class teaching', one teacher was much less enthusiastic about the notion of group instruction, claiming that by its nature it limited productivity both in terms of technical development and motivation.

T5 (F): There are all the minute physical adjustments that happen [in a one-to-one context] ... These tiny adjustments are something you can't really talk about in a class, because they're not applicable to everybody. ... You can take a piece of music in a class, but how do you know that that piece of music speaks to everybody?

Perspectives of students about positioning one-to-one in a broader context tended to focus on the respective advantages of one-to-one over group teaching. Some student-participants stated that one-to-one allowed for a more 'efficient' and 'focused' approach because it targeted individual students' needs and abilities:

FG1 (F): [When you enter the Conservatorium] there are still lots of little technical things that need to be fixed, and you need time to focus on those in a really focused way, which can't really be achieved if you're in a group situation, I don't think, because all these people have slightly different issues. You need a teacher to sit down with you and really focus on that ... It's not something that can be talked about in broad terms, so you can't cover so many different issues in broad ways, so you need to do it in a detailed way which requires a one-on-one [approach].

FG2 (M): The one-to-one lesson enables the learning to be targeted at your specific level of ability, and that's a huge difference between one-to-one lessons and classroom learning.

A relatively small number of students acknowledged the advantages of both one-to-one and other learning formats, including workshop and group activities. Perceived benefits of the latter included the motivation generated by witnessing other students learn, the competitiveness that sometimes arises, and the opportunity to learn from fellow students (FG1). One student commented: 
FG3 (M): Workshop is also valuable because you get to just see where everyone else in your age group, or in the same degree ... you just get to see what they're doing and what they're coming up with. Of course, playing music is - music's an expression of what's around us. So obviously you need to be listening and looking at the things that are around you, including other musicians. So group lessons are valuable in a different way.

Another observed that at certain times in a student's development, the value of the oneto-one approach relative to group teaching may shift. In response to a comment about the unique benefits of the one-to-one approach (including teacher enthusiasm and the 'energy' inherent in the method), this student replied:

FG3 (F): I'm going to put a bit of a dampener on it, because all of those things I also got for the five years that I was in a class environment. ... But I think, as you get technically better, you do need the one-on-one.

\section{Discussion}

Within this single small-scale study, reported experiences and perceptions of the nature and value of one-to-one tuition varied considerably, with teacher-participants indicating a variety of pedagogical styles and techniques, and student-participants a variety of learning preferences and approaches. This renders generalisations risky. If conclusions are to be drawn from this study, they may primarily reference the diversity of learning and teaching perspectives and experiences, rather than pinpointing their nature and quality. Other studies have similarly identified widely differing experiences of one-to-one tuition from teacher to teacher and student to student (Gaunt, 2010, 2011). The project team plans to broaden and deepen the scope of this present research through international collaboration with other tertiary music institutions, with one aim (among others) to establish the extent of this variability across the tertiary context, and its implications for developing 'better practice' models for one-to-one tuition.

With this proviso, it is still possible to table some broad indications about the views of participants presented in the focus groups and interviews. Participants overwhelmingly viewed the one-to-one method as invaluable, even irreplaceable, for its ability to respond to the individual, its customisable nature, and its pedagogical effectiveness. These perceived strengths may go some way towards indicating the unique value of one-to-one as a pedagogical approach in conservatoire instrumental and vocal teaching.

Both teacher and student participants also encountered some challenges with the oneto-one model, including the complexities of negotiating an appropriate teacher-student relationship; the difficulties of striking the right balance between teacher-led and studentled learning; and the necessity for one or both parties to adapt to the personality and teaching/learning style of the other.

The findings of this research corroborate Gaunt's statement that 'teachers are the musical agents, the models, and the motivating forces for their students' (2008, p. 215). Many student-participants regarded their one-to-one teacher as a musical, professional and/or personal role model, mentor or advisor, and placed high value on this mentoring 
relationship. In exploring conservatoire students' perspectives of the concept and practice of mentoring, Gaunt et al. (2012) found that one-to-one tuition indeed holds potential to be a productive mentoring environment, not least for its potential to guide students in connecting their conservatoire learning to real-world contexts and professional pathways. This important role of the one-to-one teacher in students' professional development was tabled by both student and teacher participants in this study.

Despite both students and teachers generally highly valuing the capacity to tailor one-to-one teaching to the needs and learning style of each student, interview responses revealed that several teachers consistently drew on the concept and practice of mimicry in their one-to-one practice. While a minority of student participants confirmed their need for close guidance especially in their early years of tertiary study, many reacted against this approach, wanting more autonomy in their own learning. Arguably, an over-reliance on demonstration and modelling indicates a teacher-centred rather than student-centred approach (Polifonia, 2010), potentially generating the undesirable situation reported in Persson's study in which a majority of teacher-participants tended to 'dominate their students completely' (1994, p. 88). Most teachers in this study who employed modelling or mimicry seemed to be aware (to some extent) of the potential to create dependency, incorporating it only in the first year or two of a student's tertiary studies, and tending to wean students from it by their later years of study.

Teacher-participants recognised the potential benefits of positioning one-to-one in a wider and more diverse field of pedagogical practice - more so than students, who tended to present the relative benefits of one-to-one over group teaching. Most teachers had a strong concept of the way the one-to-one approach might (or does) form part of a suite of pedagogical tools that combine to provide students with a more complete and multi-dimensional learning environment, especially considering the 'fundamentally social processes that are implicated in becoming a musician' (Juuti \& Littleton, 2010, p. 482). These tools may include master classes, workshops and studio seminars (Creech et al., 2009; Long et al., 2012), team teaching arrangements (Wöllner \& Ginsborg, 2011) and informal and peer learning (Lebler, 2008), though the latter did not feature prominently in participants' responses in this study.

The perceived benefits of collaborative learning environments, if they in fact pertain, may indicate that one-to-one need not - indeed, perhaps should not - dominate the field of tertiary vocal and instrumental learning and teaching. For students, situating one-to-one experiences within a suite of learning contexts may mitigate some identified risks with the one-to-one approach, such as an inability to adapt their learning to diverse musical contexts outside the studio (Mills, 2002), a negative impact on musical development in the absence of a healthy teacher-student relationship (Creech \& Hallam, 2010), the lack of development of some key skills necessary for professional life (Gaunt, 2010) and dependency and limited employment opportunities (Carey, 2010). Benefits of a multi-faceted approach, however, need to be understood and weighed against certain challenges inherent in collaborative learning situations. One study, for example, indicates that while master classes provide students valuable performance opportunities and generate new ideas on interpretation and technique, students also reported barriers to learning in the master class environment, including impaired concentration and performance anxiety (Creech et al., 2009). Another study revealed that team teaching was beneficial in terms of exposure to new ideas and 
gaining additional feedback, but may carry certain drawbacks for students, including limited individual attention and differences between teachers' approaches (Wöllner \& Ginsborg, 2011).

In the face of the escalating need to provide both evidence-based accounts of its effectiveness, and ways to improve its practice, there remains much to discover about the value and efficacy of the one-to-one approach in the conservatoire. The findings of this study indicate that its participants view one-to-one as essential to students' learning and development. Beyond that, experiences, practices and conceptions about what makes oneto-one teaching effective diverged considerably. Questions remain as to how to optimise one-to-one instrumental and vocal learning and teaching in the conservatoire context. Could a better understanding of the complex relationship and respective roles of teachers and students achieve more effective learning outcomes? Might these learning outcomes be enriched through a broader adoption of a collective or team-based approach? To what extent could this help overcome the 'culture of concealment' in one-to-one practice? Future research and inter-institutional collaboration may help answer these urgent questions.

\section{References}

ASSOCIATION OF EUROPEAN CONSERVATOIRES (2010) Quality Assurance and Accreditation in Higher Music Education. Amsterdam: Association of European Conservatoires.

BURT, R. \& MILLS, J. (2006) Taking the plunge: the hopes and fears of students as they begin music college. British Journal of Music Education, 23, 51-73.

BURWELL, K. (2005) A degree of independence: teachers' approaches to instrumental tuition in a university college. British Journal of Music Education, 22, 199-215.

BURWELL, K. (2006) On musicians and singers: an investigation of different approaches taken by vocal and instrumental teachers in higher education. Music Education Research, 8, 331-347.

CAREY, G. (2008) New Understanding of 'Relevant' Keyboard Pedagogy in Tertiary Institutions. Saarbrucken: Verlag Dr. Muller (VDM).

CAREY, G. (2010) Too much performing, too little learning? Reflections on pedagogical practices within the Conservatoire. Paper presented at the $18^{\text {th }}$ International Seminar of the Commission for the Education of the Professional Musician (CEPROM), 27-30 July. International Society for Music Education (ISME), Nedlands, Western Australia.

CAREY, G., LEBLER, D. \& GALL, S. (2012) Investigating the one-to-one teaching model in higher music education: developing a collaborative model of inquiry. Scientia Paedagogica Experimentali: International Journal of Experimental Research in Education, 47, 175-198.

CREECH, A., \& HALLAM, S. (2010) Interpersonal interaction within the violin teaching studio: the influence of interpersonal dynamics on outcomes for teachers. Psychology of Music, 38, 403-421.

CREECH, A., GAUNT, H., HALLAM, S. \& ROBERTSON, L. (2009) Conservatoire students' perceptions of master classes. British Journal of Music Education, 26, 315-331.

FROELICH, H. (2002) Thoughts on schools of music and colleges of education as places of 'rites and rituals': consequences for research on practising. In I. M. Hanken, S. G. Nielsen \& M. Nerland (Eds.), Research in and for Higher Music Education (pp. 149-165). Oslo: Norges Musikkhogskole.

GAUNT, H. (2008) One-to-one tuition in a conservatoire: the perceptions of instrumental and vocal teachers. Psychology of Music, 36, 215-245.

GAUNT, H. (2010) One-to-one tuition in a conservatoire: the perceptions of instrumental and vocal students. Psychology of Music, 38, 178-208. 
GAUNT, H. (2011) Understanding the one-to-one relationship in instrumental/vocal tuition in Higher Education: comparing student and teacher perceptions. British Journal of Music Education, 28, 159179.

GAUNT, H., CREECH, A., LONG, M. \& HALLAM, S. (2012) Supporting conservatoire students towards professional integration: one-to-one tuition and the potential of mentoring. Music Education Research, 14, 25-43.

HALLAM, R. (2011) Effective partnership working in music education: principles and practice. International Journal of Music Education, 29, 155-171.

HARRISON, S. (1997) Submission to the review of higher education financing and policy. Review of Higher Education Financing and Policy - Submissions. http://www.pc.gov.au/ic/research/submission/highered/ [Accessed 9 August 2012]

HARRISON, S. D. (2004) Lifelong learning in music education: A brief examination. In D. Roebuck, J. Searle \& C. McKavanagh (Eds.), Doing, Thinking, Activity, Learning: Proceedings of the 12th Annual International Conference on Post-compulsory Education and Training 1 (pp. 204-208). Brisbane: Australian Academic Press.

JUUTI, S. \& LITTLETON, K. (2010) Musical identities in transition: solo-piano students' accounts of entering the academy. Psychology of Music, 38, 481-497.

KENNELL, R. (1997) Teaching music one on one: a case study. Dialogue in Instrumental Music Education, 21, 69-81.

KENNELL, R. (2002) Systematic research in studio instruction in music. In R. Colwell \& C. Richardson (Eds.), The New Handbook of Research on Music Teaching and Learning (pp. 243-256). New York: Oxford University Press.

LEBLER, D. (2008). Popular music pedagogy: peer-learning in practice. Music Education Research, 10, 193-213.

LOCKETT, D. R. (2007) The scholar/performer: a new dimension in music research. In Proceedings of the $8^{\text {th }}$ Australasian Piano Pedagogy Conference, 2-6 July 2007. Canberra: Australian National University. http://www.appca.com.au/2007proceedings.php [Accessed 12 July 2012]

LONG, M., CREECH, A., GAUNT, H., HALLAM, S. \& ROBERTSON, L. (2012). Blast from the past: Conservatoire students' experiences and perceptions of public master classes. Musicae Scientiae, 16, 286-306.

MAZE, J. (2012) Fighting huge cuts at ANU. Advocate: Journal of the National Tertiary Education Union, $19,2,7$.

MILLS, J. (2002) Conservatoire students' perceptions of the characteristics of effective instrumental and vocal tuition. Bulletin of the Council for Research in Music Education, 153/154, 78-82.

MILLS, J. \& SMITH, J. (2003) Teachers' beliefs about effective instrumental teaching in schools and higher education. British Journal of Music Education, 20, 5-27.

MUSIC COUNCIL OF AUSTRALIA (2011) Higher Education Base Funding Review: Submission to the Department of Education, Employment and Workplace Relations. http://www.mca.org.au/ advocacy/2011-papers/16319-higher-education-base-funding-review [Accessed 7 September 2012]

PERSSON, R. (1994) Concert musicians as teachers: on good intentions falling short. European Journal for High Ability, 5, 79-91.

PERSSON, R. (1996) Brilliant performers as teachers: a case study of commonsense teaching in a conservatoire setting. International Journal of Music Education, 28, 25-36.

POLIFONIA WORKING GROUP FOR INSTRUMENTAL AND VOCAL MUSIC TEACHER TRAINING (2010). Instrumental and Vocal Teacher Education: European Perspectives [handbook]. Utrecht: AEC.

PRESLAND, C. (2005) Conservatoire student and instrumental professor: the student perspective on a complex relationship. British Journal of Music Education, 22, 237-248.

PURSER, D. (2005) Performers as teachers: exploring the teaching approaches of instrumental teachers in conservatoires. British Journal of Music Education, 22, 287-298. 
SCHMIDT, C. P. (1989) Individual differences in perception of applied music teaching feedback. Psychology of Music, 17, 110-112.

WÖLLNER, C. \& GINSBORG, J. (2011). Team teaching in the conservatoire: the views of music performance staff and students. British Journal of Music Education, 28, 301-323.

\section{Appendix}

Table 1 Teacher-participants in the study (through interviews)

\begin{tabular}{llll}
\hline \hline Teacher & Gender & Instrument group & Employment status \\
\hline T1 & M & Brass & Full time \\
T2 & M & Brass & Full time \\
T3 & F & Woodwind & Part time \\
T4 & F & Jazz Voice & Full time \\
T5 & F & Keyboard & Part time \\
T6 & F & Percussion & Full time \\
T7 & F & Classical Voice & Full time \\
T8 & M & Strings & Full time \\
\hline \hline
\end{tabular}


Table 2 Student-participants in the study (through focus groups)

\begin{tabular}{lll}
\hline \hline Gender & Level of study & Instrument group \\
\hline Focus Group A & & \\
$\mathrm{F}$ & Undergraduate & Strings \\
$\mathrm{F}$ & Undergraduate & Woodwind \\
$\mathrm{M}$ & Undergraduate & Strings \\
$\mathrm{F}$ & Undergraduate & Keyboard \\
$\mathrm{F}$ & Undergraduate & Woodwind \\
Focus Group B & & \\
$\mathrm{M}$ & Undergraduate & Classical voice \\
$\mathrm{F}$ & Postgraduate & Contemporary Voice \\
$\mathrm{M}$ & Postgraduate & Percussion \\
$\mathrm{M}$ & Undergraduate & Keyboard \\
$\mathrm{F}$ & Undergraduate & Brass \\
Focus Group C & & \\
$\mathrm{M}$ & Undergraduate & Classical voice \\
$\mathrm{F}$ & Undergraduate & Contemporary instrumentalist \\
$\mathrm{F}$ & Undergraduate & Percussion \\
$\mathrm{F}$ & Undergraduate & Strings \\
Focus Group D & & \\
$\mathrm{M}$ & Undergraduate & Classical voice \\
$\mathrm{F}$ & Postgraduate & Classical voice \\
$\mathrm{F}$ & Undergraduate & Contemporary voice \\
$\mathrm{F}$ & Undergraduate & Contemporary voice \\
Total participants & 18 & \\
\hline \hline
\end{tabular}

Gemma Carey is a Senior Lecturer in Piano and Head of Pedagogy at the Queensland Conservatorium Griffith University. She has presented and published papers in the field of performance pedagogy, curriculum and teaching and learning both nationally and internationally and works with students from pre-tertiary to doctoral level.

Catherine Grant is a Research Fellow at the Queensland Conservatorium Research Centre, Griffith University. Her research interests and publications lie in the areas of tertiary music teaching and learning, health and well-being for performing artists, and the sustainability of music genres. 